\title{
The Inclusive Potential of Physical-recreational Activity at Italian Nursery School
}

\author{
Ambretti Antinea \\ Department of Human, Philosophical and Educational Sciences, University of Salerno, Fisciano Salerno 84084, Italy
}

\begin{abstract}
In the introduction to the 2012 Italian ministry guidelines on the curriculum for nursery schools, the need to structure the curricular so that it respects the uniqueness and originality of each child attending the nursery school as well as the phases of development and training is highlighted. In particular, it is worth noting that particular attention must be given to the support of various forms of diversity, disability or disadvantage. The structuring of learning paths based on corporeity is one of the possible ways that can remove any form of obstacle promoting the inclusion and integration of the pupil with disabilities within the classroom context. The body and movement is an appealing educational environment capable of ensuring the pace of individual and individualized learning, with it being set with a scholastic context as a path in which each student experiences the use of their different abilities.
\end{abstract}

Key words: Inclusion, physical-recreational activity, kindergarten.

\section{Introduction}

In Italy, interest in the inclusion of disabled pupils in schools has led to a revision in Italian schools at all levels and educational initiatives in terms of inclusion that are, first and foremost, respectful of the differences of each person.

In line with the principles of individualization and personalization established under Law 104 of 1992 entitled Framework law for the assistance, social integration and rights of disabled people, current Italian ministerial scholastic documents define diversity as a fundamental value [1] that should therefore be promoted, from kindergarten onwards, starting with the identification of multiple and diverse paths based on the integration of disabled pupils.

Under the above mentioned law, schools from as early as kindergarten must represent a welcoming place, involving the students themselves in this task [1], starting with their own special educational needs.

Italian ministerial scholastic documents state that, as early as kindergarten, it is necessary to define and plan

Corresponding author: Ambretti Antinea, Ph.D., professor, research field: evaluation test in educational motor contexts. the scholastic curriculum based on the learner, with the specificity of their personal paths and the openings provided by the network of relationships that bind them their family and social spheres [1] in order to enhance the individual aspects of each person's personality from the uniqueness and complexity of each person, their complex identity, aspirations, capabilities and fragility, during the various phases of development and training [1].

Particular care should be afforded to the definition of special educational programs to promote feeling at ease at school [1], placing disabled pupils with all their cognitive, emotional, relational, bodily, aesthetic, ethical, spiritual and religious aspects at the center of the educational process [1].

In fact, towards the end of kindergarten, each child shows a personal ability to deal with problems and difficulties using learning models formed during their attempts to acquire new skills [2] reiterated by the WHO in the ICF classification.

A preliminary understanding of the prerequisites for social communicative relational cognitive aspectsis the starting point to ensure the step up from entry to full integration [3] aimed at the development and definition 
of an Individualized Education Program (IEP) is the life project for disabled pupils of school age and therefore includes both scholastic criteria and interventions, as well as those regarding socialization and rehabilitation, not addressed to abstract individuals, but to people who live in the here and now [1].

Indeed, IEP is an educational-operational description of the identity of a disabled pupil regarding the psycho-physical-social aspects, a summary of individualized educational teaching activities shared by a team of experts including teachers, that aims towards the development of the learning, communication and socializing potential of the disabled person [3], from the identification of residual abilities to the enhancement of all potential aspects belonging to the disabled pupil in relation to their practical inclusion in the scholastic environment.

The centrality of the disabled person referred to in the Italian ministerial scholastic documents of 2012 is the true core of the educational proposals aimed at the acceptance of diversity [1] and the consolidation of inclusive practices towards children in need of special educational activities beginning with kindergarten.

The daily scholastic experience provides a continuous opportunity for growth within an educational context aimed at well-being, questions of meaning and the gradual development of skills [1] proportionate to the type of the deficit and the relative level of severity.

At school, the alternation of primarily physical-recreational activities implicitly and explicitly stimulates the energy and potential of every child and teenager [1], both disabled and not, by facilitating access to the use of the knowledge tools needed to understand the natural, social, cultural and anthropological contexts in which students will find themselves living and working [1].

Kindergarten acknowledges this plurality of elements, which create numerous opportunities for growth, both emotional and cognitive, to develop the potential of each and every individual, as well as create an inclination in children towards trust and allowing themselves to be accompanied on their journey of knowledge [1].

\section{Methodology}

In Italy, the curriculum of kindergartens for the age group from 3 to 6 years is based on fields of experience or different environments in which children do and act and thus specific and identifiable sectors of responsibility in which children give meaning to their various activities [4]. It is the planning of different experiences that are mainly physical-recreational and which allow the natural observation of the level of potential development of skills and competencies, as well as of the various degrees and types of difficulty, for all children, especially disabled ones.

Structuring a three-year curriculum dedicated to early childhood based on fields of experience encourages teachers to embrace and value direct experience, play and proceeding by trial and error [1] which allow disabled and no-disabled children, if properly guided, to develop a personal ability to deal with problems and difficulties using learning models formed during their attempts to acquire a new skill [2].

Therefore, the fields of experience are configured as one of the possible work paths to organize activities and experiences designed to promote skills, which at this age should be seen as comprehensive and homogeneous [1]. Particular attention should be attributed to the natural needs for play, movement, expression, intimacy and sociability of the pupils which in this sense act as elements that guide the educational activity.

In Italian kindergartens, inclusion isinitially encouraged by physical-recreational activity that didactically interprets the educational aspect of movement in its various guises [5] representing a resource that is available in all fields of experience.

In the various physical-recreational experiences, what emerges is the explicit and implicit role played by the body, play and movement, so that it becomes 
relatively easy, for a teacher or a classmate, to see which and how many small changes [6] can gradually promote, stimulate and accompany the structuring of progressively more assured learning, suggesting the type of guidelines, care and responsibilities teachers should employ when creating work paths for the organization of activities and experiences [1] as a prerequisite to removing obstacles of any kind [7] in support of the various forms of diversity, disability or disadvantage [7].

In the 2012 National Guidelines for the curriculum of Italian kindergartens, the body and movement represents a first and effective form of education for pupils that like all active methods, captures the children's needs, their interest in achieving goals, as leverage for activity [5], encouraging the acquisition of essential prerequisites for gradually gaining access to more mature forms of cognitive and social and physiological skills.

In the field of experience dedicated to the body and movement, physical-recreational experience is described as a captivating educational moment capable of guaranteeing the rhythm of individual and individualized learning. It is a real alternative route where disabled pupils can experience the use of their different abilities starting from the exploration of otherwise unexpressed personal resources, thereby intertwining emotional, social and cognitive needs that manifest themselves through activities of movement and exploration as physical experiences aimed at getting a grip on the surrounding world, as well as creating an identity: we become ourselves through others [8].

Thanks to recreational-corporeal-kinesthetic activities, disabled pupils are able to achieve the personal freedom of expression and the ability to integrate different languages, alternate words and deeds, make and enjoy music and accompany narratives [1], as well as of looking for original ways to read and interpret messages transmitted by their own and others' bodies [1].
By playing, moving the whole body or only parts of it, disabled pupils learn by drawing freely from their experience and, knowledge, processing them with ongoing and independent activity [1], participating in classroom life, regardless of the type of disability and its severity.

The vicarious function performed by the body and/or its moving parts, highlighted by physical-recreational paths, allows the disabled an opportunity to gradually achieve various degrees of personal and social autonomy, from early childhood onwards, as well as study and execute possible solutions to the problems of everyday school life.

Often, especially in kindergarten, disabled pupils naturally find effective solutions through an instrumental use of corporeality in movement as the body is the point of reference from which they can give themselves a direction, experiment and formalize space and time, process and exchange symbols

The prevailing educational reference to recreational-corporeal-kinesthetic activity, especially in kindergarten, fully adheres to the scholastic philosophy of inclusion, serving as a basis for the construction of a language characterized by its own structure and rules that children learn through specific learning paths [1].

\section{Discussion}

The leading role of physical, recreational and kinesthetic activities in school curricula frees physical activity from all components that render it mechanical: physical and motor education, in the sense of education in a conscious and constructive use of ones own body is used to promote and encourage experiences that stimulate a constructive dialogue with others.

Especially in the delicate phase of kindergarten, for disabled pupils, participating in everyday school life starting from a physical-recreational experience is not just a question of understanding what and who surrounds them, i.e. sit and watch what happens [6] but implies the option of allowing teachers or classmates to 
support them in a natural and non-invasive manner.

The opportunity of coming into contact with others through play, the body and movement, especially when they first attend school, allows disabled pupils to overcome the difficulties of integration and inclusion, starting with participation in simple and natural activities that use spontaneity as the founding principle in the establishment of initial relationships with peers.

Several studies have highlighted that social factors make all bodily functions, including all functions of the brain, susceptible to social influences [9]. By contributing to the view that inclusion, primarily seen as the relationship with others, should be encouraged to ensure and achieve a necessary adjustment of the neurobiological structures. These social influences will be biologically incorporated in the altered expressions of specific genes in specific nerve cells of specific regions of the brain. These socially influenced alterations are transmitted culturally [9].

During play and movement activities, there is a natural interaction between biological and experiential factors so that disabled children may acquire many new forms of knowledge, sometimes acquiring them by virtue of daily interactions that take place in the culture and sometimes by virtue of the explicit program used by educational institutions [2].

The construction of physical-recreational paths encouraged in the 2012 ministerial documents reflects the vision. However, Vayer supports educational activity and a training environment designed around education regarding body image in an educational setting designed around the child, their age and needs [10].

Egocentrism gradually gives way to sharing, exclusion and physical and social self-exclusion give way to co-participation, the difficulties, of any kind, experienced by a classmate with a disability are understood and supported by their peers.

Any child in a recreational situation involving physical-recreational activity gradually learns to make better use of the support provided by others, accepts with a certain curious interest the need to make their personal resources available to classmates experiencing difficulties as, after all, the presence in school of children with disabilities, or in some sort of discomfort, is the source of a dynamic of relationships and interactions so unique and valuable that it, in turn, constitutes a significant and important growth opportunity for everyone [11].

\section{Conclusions}

The physical-recreational activities are therefore resources and a source of enrichment for all during the teaching-learning process teachers, students, school administrators, social and health workers, family [12] capable of achieving the fullest possible integration [13].

Hence the need to accept children's individual rates of progress; their unique way of being themselves in this world, how they experience it, discover it and get to know it, all at the same time [14].

Lewis and Norwich came to a similar conclusion in their review of specialist pedagogy [15].They suggested that teaching strategies might be arranged along a continuum from high to low intensity, rather than being arranged according to their association with a particular type of special educational need. Once again, the emphasis is on the use of a strategy rather than apparently different teaching approaches. This is important because it challenges the notion that mainstream classroom teachers do not recognize or know how to implement effective teaching practices for pupils with special needs.

Inclusive practice is about the things that staff in schools do which give meaning to the concept of inclusion [16]. Rather, inclusion involves the use of support, the ways in which teachers respond to individual differences during whole-class teaching, the choices they make about group-work and how they utilize specialist knowledge.

The need to intervene didactically in an appropriate manner is already included in the Italian ministry 
guidelines related to Law 104/92, as well as in the scholastic guidelines referred to in the 2012 segment on Italian kindergartens.

In particular, it takes note of the specificity of physical-recreational activity, highlighting its role on inclusion.

Recent Italian ministerial guidelines on schools refer to the need to invest on stimulating the substitute of intelligent corporeality as a privileged instrument for the acquisition of knowledge based on the use of the body to solve problems or do things [2].

Especially in school programs, starting with kindergarten, corporeality in its different forms of expression, including recreation primarily, can and must serve as a substitute for the need to compensate for forms of physical, cognitive or mental and physical deficiencies with respect for the specific individuality of the disability person.

\section{Reference}

[1] Italian Ministry of Education. 2012. Ministry of Education Guidelines for the Nursery and Primary School. Roma.

[2] Gardner, H. 1998. Educating to Understand. Milano: Feltrinelli. (in Italian)

[3] Ministry of Equal Opportunities. Law 104/1992. Italian Presidential Decree Frame-law on the Rights of Handicapped Persons. Rome: Italian Ministry of Equal opportunities.(in Italian)

[4] Ministry of Education. 1991. Guidelines for the Nursery and Primary School. Roma: Italian Ministry of Education. (in Italian)

[5] Le Boulch, J. 1990. Educational Sport. Roma: Armando editore. (in Italian)

[6] Canevaro, A. 2007. School Integration of Pupils with Disabilities. Thirty Years of Inclusion in the Italian School. Torino: Erickson. (in Italian)

[7] Ministry of Education. 2007. Guidelines for the Nursery and Primary School. Roma: Italian Ministry of Education. (in Italian)

[8] Vygotskij, L. S. 1990. History of the Development of the Higher Mental Functions and Other Works. Florence: Giunti.

[9] Rossi, E., Rossi, K., Garret, Y., Cozzolino, M., and Iannotti, S. 2006. "The Bioinformatics of Integrative Medical Insights: Proposals for an International Psycho Social and Cultural Bioinformatics Project.” Integrative Journal Medicine Insights 1: 7-26.

[10] Vayer, P. 2000 Mental-physical Education at School Age. Rome: Armando.

[11] Ministry of Education. 2012. Guidelines for the Nursery and Primary School. Roma: Italian Ministry of Education. (in Italian)

[12] Ianes, D. 2001. Special Didactics for Integration: Teaching That Is Sensitive to Differences. Trento: Erickson.

[13] The Office of the United Nations High Commissioner for Human Rights. 1989. Convention on the Rights of the Child. Accessed September 20, 1989. http://www.ohchr.org/EN/ProfessionalInterest/Pages/CR C.aspx

[14] Lapierre, A. 2001. From Relational Psychomotricity to the Body's Analysis of the Relationship. Rome: Armando. (in Italian)

[15] Norwich, B. 2007. Dilemmas of Difference, Inclusion and Disability: International Perspectives and Future Directions. London: Routledge.

[16] Florian, L. 2008. "Inclusion: Special or Inclusive Education: Future Trends.” British Journal of Special Education 35: 202-8. 